\title{
PENGARUH PROMOSI KESEHATAN METODE AUDIO VISUAL DAN METODE BUKU SAKU TERHADAP PENINGKATAN PENGETAHUAN PENGGUNAAN MONOSODIUM GLUTAMAT (MSG) PADA IBU RUMAH TANGGA
}

\author{
Surya Wibowo, Dyah Suryani \\ Fakultas Kesehatan Masyarakat, Universitas Ahmad Dahlan Yogyakarta
}

\begin{abstract}
ABSTRAK
Latar Belakang : Monosodium Glutamat (MSG) banyak dipakai untuk keperluan rumah tangga maupun industri makanan dan diperjualbelikan secara bebas. MSG biasa digunakan sebagai penyedap makanan. Mengkonsumsi MSG secara berlebihan dapat meningkatkan risiko berbagai penyakit dan juga dapat mempengaruhi kecerdasan. Salah satu cara untuk mengendalikan penggunaan MSG dalam pangan olahan sesuai dengan batasan maksimum perharinya, agar penggunaan penyedap tidak melebihi dosisnya dan aman dalam penggunaannya bagi masyarakat maka dilakukan promosi kesehatan dengan tujuan untuk menyampaikan dan menyebarkan informasi kesehatan yang diharapkan dapat meningkatkan pengetahuan masyarakat tentang penggunaan MSG.

Metode : Penelitian ini merupakan penelitian quasi experimental dengan rancangan penelitian one-group pretest-postest design. Subyek penelitian ini adalah ibu rumah tangga yang berjumlah 60 orang.

Hasil Penelitian : Hasil analisis bivariat menunjukkan bahwa terdapat pengaruh promosi kesehatan baik metode audio visual dengan $p=0,00$, maupun metode buku saku dengan $p=$ 0,00 , terhadap peningkatan pengetahuan penggunaan MSG. Tidak terdapat perbedaan rerata antara kelompok perlakuan metode audio visual dan kelompok perlakuan metode buku saku dengan $p=0,817$.

Kesimpulan : Ada pengaruh promosi kesehatan metode audio visual dan promosi kesehatan metode buku saku terhadap peningkatan pengetahuan penggunaan MSG. Tidak terdapat perbedaan rerata antara kelompok promosi kesehatan metode audio visual dan kelompok promosi kesehatan metode buku saku.
\end{abstract}

Kata Kunci : Promosi Kesehatan, Audio Visual, Buku Saku, Pengetahuan Penggunaan MSG, Ibu Rumah Tangga.

\begin{abstract}
Background: Monosodium Glutamate (MSG) was mainly consumed for household and food industry and it was freely sold. MSG has been long known by housewife because it is usually used as food flavoring. Overconsumption of MSG can cause several diseases, for example it can affect intelligence. One of the ways in controlling the application of MSG in food production with the maximum-application degree per day, so that there is no overconsumption of MSG, is to perform health promotion on the purpose of conveying and spreading information about health that it could improve people's knowledge about MSG application.

Methods: This was a quasi experimental study with one-group pretest-posttest design. There were 60 housewives as the respondent of this study.

Results: The result of bi-variant analysis indicated that there was effect of health promotion both via audio visual method with $p=0.00$, and pocket book with $p=0,00$, on the improvement of knowledge about MSG application. There was no different means between the audio-visual treatment group and the pocket book treatment group with $p=0.817$.

Conclusion : There was effect of health promotion both with audio-visual method and pocket book method on the improvement of knowledge about MSG application. There was no different
\end{abstract}


means between the group of health promotion with audio-visual method and the group of health promotion with pocket book method.

Keywords: Health promotion, Audio visual, pocket book, knowledge on MSG application, housewife.

\section{PENDAHULUAN}

Monosodium glutamat (MSG) banyak dipakai untuk keperluan rumah tangga maupun industri makanan dan diperjualbelikan secara bebas. Bahan penguat rasa sudah lama akrab dikalangan ibu rumah tangga karena biasa digunakan sebagai penyedap makanan. Produk-produk makanan yang beredar dipasaran sekarang ini banyak mengandung macam-macam bahan aditif makanan, salah satu contohnya penguat cita rasa. ${ }^{1}$

MSG dalam jumlah tertentu masih dianggap aman, namun demikian, untuk kesehatan konsumen, sebagai antisipasi adanya efek buruk yang mungkin terjadi bila mengkonsumsi dalam jumlah besar, penggunaannya harus dibatasi. Beberapa negara industri dan maju menetapkan konsumsi MSG yang masih bisa ditoleransi sebesar 0,3-1 gram per hari. ${ }^{2}$ Selama puluhan tahun MSG masih dikaitkan dengan penyebab penyakit kanker, serangan jantung, obesitas, asma, serta penyakit lainnya, bahkan berpengaruh pada kecerdasan. ${ }^{3}$

Promosi kesehatan mempunyai peranan yang sangat penting dalam proses pemberdayaan masyarakat, yaitu memperoleh pembelajaran dari, oleh dan bersama masyarakat sesuai dengan lingkungan sosial budaya setempat, agar masyarakat dapat menolong dirinya sendiri dibidang kesehatan. ${ }^{4}$

Promosi kesehatan tidak lepas dari media karena melalui media, pesan-pesan yang disampaikan dapat lebih menarik dan dipahami, sehingga sasaran dapat mempelajari pesan tersebut dan sasaran dapat memutuskan untuk mengadopsinya perilaku yang positif. ${ }^{5}$ Metode penyampaian pesan dan informasi dalam promkes diantaranya adalah metode audio visual (lihat-dengar) dan metode cetak (buku saku) yang masing-masing metode memiliki kelebihan dan kekurangan.

Penggunaan MSG di desa ini berdasarkan observasi yang telah dilakukan oleh peneliti pada tanggal 10 Maret 2013, dari 12 ibu rumah tangga yang diobservasi, 11 orang diantaranya pernah dan masih menggunakan MSG sebagai penyedap rasa masakannya. Sampel tidak mengetahui dosis/takaran penggunaan MSG bahkan hanya dengan menggunakan perkiraan saja, dan sebagian dari sampel berasumsi bahwa masakan yang tidak ditambahi MSG akan terasa kurang enak.

Penelitian ini bertujuan untuk mengetahui perbedaan pengaruh promosi kesehatan metode audio visual dan metode buku saku terhadap peningkatan pengetahuan penggunaan monosodium glutamat (MSG) pada ibu rumah tangga di Dusun Soko Desa Gadingsari Kecamatan Sanden Kabupaten Bantul.

\section{METODE PENELITIAN}

Penelitian ini merupakan penelitian quasi experimental dengan rancangan penelitian one-group pretest-postest design. ${ }^{6}$ Subyek dalam penelitian ini adalah ibu rumah tangga sebanyak 60 orang. Analisis data yang digunakan yaitu analisis univariat (deskriptif) dan analisis bivariat. 


\section{HASIL PENELITIAN DAN PEMBAHASAN}

\section{A. Hasil Penelitian}

a. Deskripsi Lokasi Penelitian

Dusun Soko merupakan salah satu dusun yang terletak di Desa Gadingsari Kecamatan Sanden Kabupaten Bantul yang memiliki penduduk sebanyak 669 jiwa dan terdiri dari 172 Kepala Keluarga (KK). Daerah ini berada di sebelah barat daya dari lbu Kota Kabupaten Bantul. ${ }^{7}$

b. Karakteristik Responden

Tabel 1. Karakteristik Responden Penelitian

\begin{tabular}{|c|c|c|}
\hline Variabel & Jumlah Responden & Persentase \\
\hline \multicolumn{3}{|l|}{ Umur } \\
\hline 15-25 Tahun & 5 & $8,33 \%$ \\
\hline 26-49 Tahun & 55 & $91,6 \%$ \\
\hline \multicolumn{3}{|l|}{ Pendidikan } \\
\hline Tidak Sekolah & 1 & $1,6 \%$ \\
\hline Tidak Tamat SD & 3 & $5,0 \%$ \\
\hline SD & 5 & $8,3 \%$ \\
\hline SMP/MTS & 13 & $21,6 \%$ \\
\hline SMA/SMK/MA & 30 & $50 \%$ \\
\hline Perguruan Tinggi & 8 & $13,3 \%$ \\
\hline \multicolumn{3}{|l|}{ Pekerjaan } \\
\hline Buruh & 8 & $13,3 \%$ \\
\hline Petani & 7 & $11,6 \%$ \\
\hline Karyawan & 5 & $8,33 \%$ \\
\hline Pedagang & 10 & $16,6 \%$ \\
\hline Wiraswasta & 17 & $28,3 \%$ \\
\hline PNS & 3 & $5 \%$ \\
\hline Lain-lain (IRT) & 10 & $16,6 \%$ \\
\hline \multicolumn{3}{|l|}{ Penghasilan } \\
\hline$<$ UMR & 44 & $73,3 \%$ \\
\hline$\geq$ UMR & 16 & $26,6 \%$ \\
\hline
\end{tabular}

Berdasarkan Tabel 1., hasil penelitian terhadap 60 orang jumlah responden, dengan umur minimal 15 tahun dan umur maksimal adalah 49 tahun. Mayoritas rentang umur responden adalah 26-49 tahun yaitu sebanyak 55 orang responden $(91,6 \%)$, tingkat pendidikan diketahui bahwa responden mayoritas memiliki tingkat pendidikan SMA/SMK/MA yaitu sebanyak 30 orang responden $(50 \%)$, tingkat pekerjaan diketahui bahwa responden mayoritas memiliki pekerjaan sebagai wiraswasta yaitu sebanyak 17 orang responden $(28,3 \%)$ dan tingkat penghasilan dapat diketahui bahwa 44 responden $(73,3 \%)$ memiliki penghasilan di bawah rata-rata UMR.

\section{c. Analisis Data}

\section{1) Analisis Univariat}

Tabel 2. Hasil analisis univariat

\begin{tabular}{lcccc}
\hline Tingkat Pengetahuan & \multicolumn{2}{c}{ Pre-test } & \multicolumn{2}{c}{ Pos-test } \\
\cline { 2 - 5 } & $\begin{array}{c}\text { Jumlah } \\
\text { (orang) }\end{array}$ & $\%$ & $\begin{array}{c}\text { Jumlah } \\
\text { (orang) }\end{array}$ & $\%$ \\
\hline Audio Visual & & & & \\
$\quad$ Baik & 23 & $76,6 \%$ & 29 & $96,6 \%$ \\
$\quad$ Kurang baik & 7 & $23,3 \%$ & 1 & $3,33 \%$ \\
\hline Buku Saku & 23 & $76,6 \%$ & 30 & $100 \%$ \\
$\quad$ Baik & 7 & $23,3 \%$ & 0 & $0 \%$ \\
$\quad$ Kurang Baik & & & & \\
\hline
\end{tabular}


2) Analisis Bivariat

Tabel 3. Hasil Analisis Uji Wilcoxon Promosi Kesehatan Metode Audio Visual Terhadap Peningkatan Pengetahuan Penggunaan MSG Pada lbu Rumah Tangga Di Dusun Soko Desa Gadingsari Kecamatan Sanden Kabupaten Bantul

\begin{tabular}{ccccc}
\hline Kelompok & $\mathrm{N}$ & $\begin{array}{c}\text { Median } \\
\text { (minimum-maksimum) }\end{array}$ & Rerata \pm SD & $P$ \\
\hline Pretest & 30 & $86,5(53,8-100)$ & $82,267 \pm 14,89$ & 0,00 \\
\hline Postest & 30 & $96,1(65,3-100)$ & $94,2 \pm 7,13$ & \\
\hline
\end{tabular}

Tabel 4. Hasil Analisis Uji Wilcoxon Promosi Kesehatan Metode Buku Saku Terhadap Peningkatan Pengetahuan Penggunaan MSG Pada lbu Rumah Tangga Di Dusun Soko Desa Gadingsari Kecamatan Sanden Kabupaten Bantul

\begin{tabular}{ccccc}
\hline Kelompok & $\mathrm{N}$ & $\begin{array}{c}\text { Median } \\
\text { (minimum-maksimum) }\end{array}$ & Rerata \pm SD & $P$ \\
\hline Pretest & 30 & $84,6(50-100)$ & $81,37 \pm 13,14$ & 0,00 \\
\hline Postest & 30 & $92,3(73-100)$ & $92,53 \pm 6,55$ & \\
\hline
\end{tabular}

\section{B. Pembahasan}

\section{Perbedaan Tingkat Pengetahuan Responden Tentang Penggunaan MSG Sebelum dan Setelah Dilakukan Promosi Kesehatan Metode Audio Visual}

Berdasarkan analisis bivariat peningkatan pengetahuan ibu rumah tangga tentang penggunaan MSG, terdapat perbedaan nilai rerata antara sebelum dan setelah dilakukan promosi kesehatan metode audio visual. Pada saat pre-test (sebelum dilakukan promosi kesehatan) nilai mean 82,267 . Pada saat post-test (setelah dilakukan promosi kesehatan) nilai mean 94,2. Terdapat perbedaan rerata pengetahuan responden antara sebelum dan setelah dilakukan promosi kesehatan metode audio visual sebesar 11,93. Hal ini menunjukkan terjadi peningkatan pengetahuan responden tentang penggunaan MSG sebelum dan setelah dilakukan promosi kesehatan metode audio visual.

Nilai probabilitas dari uji Wilcoxon adalah $0,00(0,00<0,05)$ maka $\mathrm{Ha}$ diterima dan Ho ditolak. Hal ini menunjukan bahwa promosi kesehatan metode audio visual tentang penggunaan MSG pada ibu rumah tangga di Dusun soko Desa Gadingsari Kecamatan Sanden Kabupaten Bantul menyebabkan tingkat pengetahuan berbeda (meningkat) dibandingkan sebelum diberikan promosi kesehatan metode audio visual. Ini berarti promosi kesehatan metode audio visual berpengaruh terhadap peningkatan pengetahuan penggunaan MSG pada ibu rumah tangga di Dusun Soko Desa Gadingsari Kecamatan Sanden Kabupaten Bantul.

Keberhasilan pelaksanaan promosi kesehatan metode audio visual tentang penggunaan MSG pada ibu rumah tangga di Dusun Soko Desa Gadingsari Kecamatan Sanden Kabupaten Bantul disebabkan oleh kesiapan peneliti dalam mempersiapkan materi promosi kesehatan yaitu tentang penggunaan MSG, tenaga penyuluh yang berkompeten dan alat-alat bantu yang digunakan yang menunjang dalam pelaksanaan promosi kesehatan. Disebut media pendidikan karena alat-alat tersebut merupakan alat saluran (channel) untuk menyampaikan kesehatan karena alat-alat tersebut digunakan untuk mempermudah penerimaan pesan-pesan kesehatan bagi masyarakat atau klien. ${ }^{4,8}$

Pelaksanaan penyuluhan gizi tentang makanan sehat dan gizi seimbang dapat meningkatkan pengetahuan dan sikap ibu di Desa Merek Raya 
Kecamatan Raya Kabupaten Simalungun. ${ }^{9}$ Perubahan pengetahuan tersebut dapat dilihat dari hasil selisih antara sebelum penyuluhan gizi tentang makanan sehat dan gizi seimbang adalah kategori cukup $(57,4 \%)$, setelah penyuluhan pengetahuan ibu menjadi baik (77,9\%). Sikap ibu sebelum penyuluhan gizi adalah kategori cukup (76,5\%), sesudah penyuluhan gizi sikap ibu menjadi baik (85,3\%). Hasil uji menunjukkan ada perbedaan sesudah perlakuan, yaitu pengetahuan dengan nilai $t=-17,960$ dan $p=0,000$, sikap dengan nilai $t=-24,587$ dan $p=0,000$. Kesimpulan dari penelitian ini adalah bahwa ada pengaruh penyuluhan terhadap peningkatan pengetahuan ibu dan perubahan sikap ibu tentang makanan sehat dan gizi seimbang. ${ }^{9}$

\section{Perbedaan Tingkat Pengetahuan Responden Tentang Penggunaan MSG Sebelum dan Setelah Dilakukan Promosi Kesehatan Metode Buku Saku}

Berdasarkan analisis bivariat pengetahuan ibu rumah tangga tentang penggunaan MSG dalam promosi kesehatan metode buku saku, terdapat perbedaan nilai rerata antara sebelum dan setelah dilakukan promosi kesehatan metode buku saku. Pada saat pre-test (sebelum dilakukan promosi kesehatan metode buku saku) nilai mean 81,37 . Pada saat post-test (setelah dilakukan promosi kesehatan metode buku saku) nilai mean 92,53. Terdapat perbedaan rerata pengetahuan responden antara sebelum dan setelah dilakukan promosi kesehatan metode buku saku sebesar 11,16. Hal ini menunjukkan terjadi peningkatan pengetahuan responden tentang penggunaan MSG sebelum dan setelah dilakukan promosi kesehatan metode buku saku.

Nilai probabilitas dari uji Wilcoxon adalah $0,00(0,00<0,05)$ maka Ha diterima dan Ho ditolak. Hal ini menunjukan bahwa promosi kesehatan metode buku saku tentang penggunaan MSG pada ibu rumah tangga di Dusun Soko Desa Gadingsari Kecamatan Sanden Kabupaten Bantul menyebabkan tingkat pengetahuan berbeda (meningkat) dibandingkan sebelum diberikan promosi kesehatan metode buku saku. Ini berarti promosi kesehatan metode buku saku berpengaruh terhadap peningkatan pengetahuan penggunaan MSG pada ibu rumah tangga di Dusun Soko Desa Gadingsari Kecamatan Sanden Kabupaten Bantul.

Penggunaan media intervensi untuk melakukan promosi kesehatan diantaranya harus memenuhi beberapa aspek agar media intervensi mudah diterima dan dipahami oleh kelompok sasaran. Media cetak sebagai media intervensi yang digunakan diantaranya harus menimbulkan minat pada kelompok sasaran untuk membaca pesan yang terdapat didalamnya.

Pemberian buku saku mengenai jajanan sehat dapat meningkatkan pengetahuan pada responden. ${ }^{10}$ Perubahan pengetahuan tersebut dapat dilihat dari hasil selisih antara rerata pengetahuan awal dan pengetahuan akhir responden. Pada kelompok intervensi nilai perubahan atau selisih rerata pengetahuan akhir dan awal sebesar 2,025. Ada pengaruh pemberian modul tentang gizi anak terhadap peningkatan pengetahuan responden. Pemberian media berupa modul meningkatkan rerata pengetahuan responden dari 17,93 menjadi 20,13 dengan perbedaan skor $2,20 .{ }^{10}$ 


\section{Perbedaan Rerata Tingkat Pengetahuan Responden Tentang Penggunaan MSG Setelah Dilakukan Promosi Kesehatan Metode Audio Visual dan Setelah Dilakukan Promosi Kesehatan Metode Buku Saku}

Berdasarkan hasil uji bivariat peningkatan pengetahuan responden tentang penggunaan MSG, terdapat perbedaan nilai rerata antara promosi kesehatan metode audio visual dan promosi kesehatan metode buku saku. Pada saat dilakukan promosi kesehatan metode audio visual diperoleh nilai mean 11,94. Pada saat dilakukan promosi kesehatan metode buku saku diperoleh nilai mean 11,29. Hal ini menunjukkan bahwa promosi kesehatan metode audio visual memiliki rerata nilai mean yang lebih besar dibandingkan dengan promosi kesehatan metode buku saku dengan selisih nilai mean nya yaitu 0,65 .

Nilai probabilitas dari uji Mann-Whitney adalah $0,817(0,817>0,05)$ maka Ha ditolak dan Ho diterima. Hal ini menunjukkan bahwa tidak terdapat perbedaan rerata antara kelompok yang dilakukan promosi kesehatan metode audio visual dan kelompok yang dilakukan promosi kesehatan metode buku saku.

Promosi kesehatan metode audio visual (lihat-dengar) lebih merangsang dalam penyampaian pesan-pesan/informasi yang disampaikan karena responden dapat melihat dan responden juga dapat mendengarkan isi pesan tersebut. Sehingga metode audio visual memiliki nilai rerata mean lebih tinggi dibandingkan dengan metode buku saku (lihat). Menurut Edgar Dale (1964) dalam Nursalam dan Efendi (2009) yang digambarkan dalam kerucut Edgar Dale, membaca akan mengingat $10 \%$ dari materi yang dibaca, mendengar akan mengingat $20 \%$ dari yang didengar, melihat akan mengingat $30 \%$ dari apa yang dilihat, mendengar dan melihat akan mengingat $50 \%$ dari apa yang didengar dan dilihat. ${ }^{11}$

Hasil penelitian ini tidak sesuai dengan teori Edgar Dale (1964) dalam Nursalam dan Efendi (2009) yang digambarkan dalam kerucut Edgar Dale, menyatakan bahwa membaca akan mengingat 10\% (media cetak) dari materi yang dibaca, mendengar akan mengingat $20 \%$ dari yang didengar, melihat akan mengingat 30\% dari apa yang dilihat, mendengar dan melihat akan mengingat $50 \%$ (audio visual) dari apa yang didengar dan dilihat. Hal ini dimungkinkan oleh karena keterbatasan waktu yang dimiliki oleh responden dalam pelaksanaan promosi kesehatan baik metode audio visual maupun metode buku saku.

Faktor keberhasilan promosi kesehatan banyak faktor yang perlu diperhatikan terhadap sasaran dalam keberhasilan promosi kesehatan, diantaranya adalah : tingkat pendidikan, tingkat sosial ekonomi, adat istiadat, kepercayaan masyarakat, ketersediaan waktu dari masyarakat. ${ }^{12}$

\section{SIMPULAN DAN SARAN}

\section{A. Simpulan}

1. Terdapat pengaruh promosi kesehatan metode audio visual terhadap peningkatan pengetahuan penggunaan monosodium glutamat (MSG) pada ibu rumah tangga di Dusun Soko Desa Gadingsari Kecamatan Sanden Kabupaten Bantul.

2 Terdapat pengaruh promosi kesehatan metode buku saku terhadap peningkatan pengetahuan penggunaan monosodium glutamat (MSG) pada ibu rumah tangga di Dusun Soko Desa Gadingsari Kecamatan Sanden Kabupaten Bantul. 
3. Tidak terdapat perbedaan rerata antara kelompok yang telah diberi promosi kesehatan metode audiovisual dan kelompok yang telah diberi promosi kesehatan metode buku saku terhadap peningkatan pengetahuan penggunaan monosodium glutamat (MSG) pada ibu rumah tangga di Dusun Soko Desa Gadingsari Kecamatan Sanden Kabupaten Bantul.

\section{B. Saran}

1. Bagi Puskesmas Kecamatan Sanden hendaknya melakukan pembinaan dalam bentuk promosi kesehatan secara rutin hingga pada monitoring sikap dan perilaku mengenai penggunaan Bahan Tambahan Makanan (BTM).

2. Bagi peneliti selanjutnya diharapkan untuk dapat meneliti sejauh mana pengaruh promosi kesehatan metode audio visual dan promosi kesehatan metode buku saku terhadap sikap dan perilaku ibu rumah tangga dalam menggunakan MSG dalam makanan.

\section{DAFTAR PUSTAKA}

1. Afrianti, L.H., Teknologi Pengawetan Pangan, Cetakan Kesatu, Penerbit Alfabeta, Bandung. Hal. 2, 18, 113, 123, 129, 2008.

2. Yuliarti, N., Awas Berbahaya Dibalik Lezatnya Makanan, Penerbit ANDI, Edisi satu, Yogyakarta. Hal. 99-101, 105, 2007.

3. Amirullah, Konsumsi MSG Indonesia Meningkat, http://www.tempo.co/ $\mathrm{read} / \mathrm{news} / 2012 / 01 / 19 / 060378387 /$ Konsumsi-MSG-Indonesia-Meningkat, diakses pada tanggal 6 Maret 2013 pukul 19.07 WIB, Yogyakarta, 2012.

4. Fitriani, S., Promosi Kesehatan, Edisi pertama cetakan pertama, Penerbit Graha IImu, Yogyakarta. Hal. 1-2, 87, 176-180, 2011.

5. Notoatmodjo, S., Promosi Kesehatan Teori dan Aplikasi, Edisi revisi, Penerbit Rineka Cipta, Jakarta. Hal 291-293, 2010.

6. Sugiyono, Metodologi Penelitian Kuantitatif Kualitatif dan $R \& D$, Cetakan kedelapan, Penerbit Alfabeta, Bandung. Hal. 74, 81-82, 2009.

7. Pemerintah Kabupaten Bantul, Data Kecamatan, www.bantulkab.go.id diakses pada tanggal 10 Maret 2013 pukul 12.09 WIB, Yogyakarta, 2013.

8. Fitriani, S., Promosi Kesehatan, Edisi pertama cetakan pertama, Penerbit Graha IImu, Yogyakarta. Hal. 1-2, 87, 176-180, 2011.

9. Saragih, F.S., Pengaruh Penyuluhan Terhadap Pengetahuan Dan Sikap Ibu Tentang Makanan Sehat Dan Gizi Seimbang Di Desa Merek Raya Kecamatan Raya Kabupaten Simalungun, Skripsi, Fakultas Kesehatan Masyarakat Universitas Sumatera Utara, Medan, 2010.

10. Artiwi, T., Pengaruh Pemberian Buku Saku Tentang Jajanan Sehat Terhadap Tingkat Pengetahuan Jajanan Sehat Pada Murid Kelas V di Sekolah Dasar Negeri Glagah, Kelurahan Warungboto, Kecamatan Umbulharjo, Kota Yogyakarta, skripsi, Fakultas Kesehatan Masyarakat Universitas Ahmad Dahlan, Yogyakarta, 2011.

11. Dale, E., 1964 dalam Nursallam dan Efendy, F., Pendidikan Dalam Keperawatan, Penerbit Salemba Medika, Jakarta. Hal. 204, 2009.

12. Effendy, N., Dasar-Dasar Keperawatan Masyarakat, Edisi 2, EGC, Jakarta. Hal. 236, 1998. 
